\title{
THE ARBITRATION AGREEMENT CONCLUDED WITHIN THE INTERNATIONAL COMMERCIAL ARBITRATION: BASIS FOR THE CHOICE AND ISSUES OF THE APPLICABLE LAW
}

\author{
Irina A. Stepanova \\ Notary of Volgograd, Volgograd, Russian Federation; \\ Peoples' Friendship University of Russia, Moscow, Russian Federation
}

Introduction: nowadays in the conditions of increase in number of civil conflicts complicated by a foreign element the problem of searching an appropriate way to resolve them is of great urgency. The practice analysis shows that conflicting parties wishing to keep privacy and "healthy" partnership increasingly refer the disputes arising between them to the International Commercial Arbitration and conclude the relevant agreements on it. In spite of the fact that a strict and harmonized system of legal sources is developing in the sphere under consideration in Russia, the presence of a foreign element in the arbitration agreement concluded within the international commercial arbitration predetermines the emergence of a conflict issue, which is not solved obviously. In this regard the main aim of this research is defining the specificity of the arbitration agreement concluded within the International Commercial Arbitration predetermining the emergence of the conflict issue, which requires a special solution. Methods: the methodological framework for the research is general scientific methods (the analysis, synthesis, induction, deduction, generalization, etc.) and specific scientific methods (technical legal method, a method of interpretation of law, etc.). Results: the author reveals the specificity of the arbitration agreement within the International Commercial Arbitration, proposes the solution of the conflict issue arising in case when parties do not include the conditions on applicable law in the text of such an agreement. Conclusions: the author concludes that the agreement on referring a dispute to the International Commercial Arbitration serves as a precondition of its trial in a similar arbitration, its contents depend on the will of the parties, and its specificity is caused by the existence of a foreign element in legal relationships. In order to exclude the problems connected with the impossibility to define the applicable law to the relations of the parties following from the agreement on referring the disputes to ICA, the author offers to add a provision to cl. 1211 of the Civil Code of the Russian Federation stating that in case of lack of the direct instruction in the international contract, law or the agreement of the parties to the arbitration agreement (clause) the law of the state of the arbitration place shall apply.

Key words: agreement, dispute, arbitration agreement, international commercial arbitration, foreign element, applicable law.

Citation. Stepanova I.A. The Arbitration Agreement Concluded within the International Commercial Arbitration: Basis for the Choice and Issues of the Applicable Law. Legal Concept, 2019, vol. 18, no. 1, pp. 23-29. (in Russian). DOI: https://doi.org/10.15688/lc.jvolsu.2019.1.3

УДК 347.1

Дата поступления статьи: 05.02.2019

ББК 67.410 .1

Дата принятия статьи: 22.02.2019

\section{СОГЛАШЕНИЕ О МЕЖДУНАРОДНОМ КОММЕРЧЕСКОМ АРБИТРАЖЕ: ОСНОВАНИЕ ВЫБОРА И ВОПРОСЫ ПРИМЕНИМОГО ПРАВА}

\author{
Ирина Александровна Степанова \\ Нотариус города Волгограда, г. Волгоград, Российская Федерация; \\ Российский университет дружбы народов, г. Москва, Российская Федерация
}


Введение: в настоящее время в условиях увеличения количества гражданско-правовых конфликтов, осложненных иностранным элементом, актуализируется проблема поиска оптимального способа их урегулирования. Анализ практики показывает, что конфликтующие стороны, желая сохранить конфиденциальность и «здоровые» партнерские отношения, все чаще стали передавать возникающие между ними споры на рассмотрение в порядке международного коммерческого арбитража (МКА) и заключать соответствующие соглашения об этом. Несмотря на то что в России постепенно стала складываться строгая и гармонизированная система правовых источников в рассматриваемой сфере, наличие иностранного элемента в арбитражном соглашении, заключаемом в рамках МКА, предопределяет возникновение коллизионного вопроса, решить который не всегда представляется возможным. В связи с этим основной целью настоящего исследования выступает определение специфики арбитражного соглашения, заключаемого в рамках международного коммерческого арбитража, предопределяющего возникновение коллизионной проблемы, требующей особого решения. Методы: в ходе исследования применялись общенаучные (анализ, синтез, индукция, дедукция, обобщение и др.) и частнонаучные методы (формально-юридический, метод толкования норм права и др.). Результаты: в работе выявлена специфика арбитражного соглашения в рамках МКА, предложено решение коллизионной проблемы, возникающей в случае невключения сторонами в текст такого соглашения условия о применимом праве. Выводы: в результате проведенного исследования определено, что соглашение о передаче спора в международный коммерческий арбитраж служит предпосылкой его разбирательства в подобном арбитраже, его содержание зависит от воли сторон, а специфика обусловлена наличием иностранного элемента в правоотношении. В целях исключения возможности возникновения проблемы, связанной с невозможностью определить применимое право к отношениям сторон, вытекающим из соглашения о передаче споров на рассмотрение в МКА, автором предлагается дополнить ст. 1211 ГК РФ положением, согласно которому в случае отсутствия прямого указания в международном договоре, законе или соглашении сторон к арбитражному соглашению (оговорке) применяется право государства места проведения арбитражного разбирательства.

Ключевые слова: соглашение, спор, арбитражное соглашение, международный коммерческий арбитраж, иностранный элемент, применимое право.

Цитирование. Степанова И. А. Соглашение о международном коммерческом арбитраже: основание выбора и вопросы применимого права // Legal Concept = Правовая парадигма. - 2019. - Т. 18, № 1. - С. 2329. - DOI: https://doi.org/10.15688/lc.jvolsu.2019.1.3

\section{Введение}

Одним из условий благоприятного развития экономики нашего государства и поддержания ее стабильности является наличие таких правовых механизмов, которые способствовали бы доверию иностранных партнеров и, соответственно, отвечали бы как потребностям современного международного гражданского оборота, так и общепризнанным принципам и нормам. Учитывая особый характер международной коммерческой деятельности и специфику конфликтов, возникающих в процессе ее осуществления, можно заключить, что они требуют самого тщательного и всестороннего рассмотрения лицами, являющимися экспертами в сфере международного частного права. Как правило, субъекты международной коммерческой деятельности желают сохранить конфиденциальность рассматриваемого конфликта и проявляют стремление к дальнейшему сотрудничеству и сохра- нению «здоровых» деловых отношений, тяжело устанавливаемых хозяйственных связей с иностранным участием. Презумпция добросовестности и добронамеренности сторон предполагает действенное разрешение спора "communis opinio doctorum ex lex et bonae fides» [3, с. 108; 12, с. 103]. Следствием перечисленных обстоятельств является планомерное увеличение количества споров, которые передаются на рассмотрение в порядке международного коммерческого арбитража (далее - МКА) [7; 8].

Последние пять лет российские законодатели уделяли пристальное внимание третейскому судопроизводству вообще и международному арбитражу в частности [2, с. $8 ; 14]$, поэтому в Российской Федерации стала складываться строгая и гармонизированная система правовых источников в этой сфере. Основой, то есть своеобразным lexgeneralis, здесь выступает Федеральный закон от 29 декабря 2015 г. № 382-Ф3 (ред. от 25.12.2018) «Об ар- 
битраже (третейском разбирательстве) в Российской Федерации» [18], а в части деятельности международного коммерческого арбитража используется специальный норматив (lexspecialis) - Закон РФ от 7 июля 1993 г. № 5338-1 (ред. от 25.12.2018) «О международном коммерческом арбитраже» [6] (далее Закон о МКА). Однако деятельность МКА и на основе п. 4 ст. 15 Конституции РФ, и в силу специфики разбирательства регулируется еще значительным количеством международных источников в форме как международных соглашении, так и рекомендательных актов.

\section{Соглашение о международном коммерческом арбитраже как основание выбора способа урегулирования спора}

Анализ ст. 1 Закона о МКА позволяет выделить ряд споров, которые могут быть переданы ему для рассмотрения и дальнейшего урегулирования. Общим основанием, допускающим такую возможность, выступает факт наличия соглашения сторон о такой передаче. Характер спора, который может быть передан в МКА, безусловно, определяется гражданско-правовыми отношениями конфликтующих сторон, связанными и непосредственно вытекающими из осуществляемой ими внешнеторговой и иной международной экономической деятельности. При этом обязательными условиями для передачи спора в МКА, помимо соответствующего соглашения сторон, являются: местонахождение одной из сторон за границей, или нахождение за границей места исполнения значительной части обязательств, или место, с которым наиболее тесно связан предмет спора, находится за границей. К непосредственной компетенции МКА относятся и инвестиционные споры.

Таким образом, из содержания указанной нормы видно, что соглашение о передаче спора в МКА служит предпосылкой его разбирательства в подобном арбитражном суде. Большинство авторов подчеркивают, что такого рода договор является отражением принципа добровольности обращения к арбитражному разбирательству, без которого оно фактически невозможно [4; 9, с. $648 ; 19$, с. 348$]$.
А с другой стороны, заключение контрагентами арбитражного соглашения является правообразующим юридическим фактом, порождающим право МКА на рассмотрение конкретных споров между сторонами.

По своей юридической природе, содержанию, форме, способам реализации (видам), применимым принципам (добровольности и автономности) и т. п. арбитражное соглашение, заключенное для рассмотрения споров в международном коммерческом арбитраже и арбитраже внутренних споров, по сути, совпадает и имеет один и тот же юридический характер. Этот факт подтверждает сравнение содержания ст. 7-9 Закона РФ от 7 июля 1993 г. № 5338-1 (ред. от 25.12.2018) «О международном коммерческом арбитраже» и аналогичных норм ст. 7-9 Федерального закона от 29 декабря 2015 г. № 382-Ф3 (ред. от 25.12.2018) «Об арбитраже (третейском разбирательстве) в Российской Федерации», тексты которых фактически идентичны.

\section{Проблема выбора применимого права \\ в соглашении о международном коммерческом арбитраже}

Наличие в правоотношении иностранного элемента несет в себе определенную специфику арбитражного соглашения в рамках МКА. Как и в большинстве гражданско-правовых обязательств, в этом случае необходимо решить коллизионную проблему, то есть проблему выбора применимого права [13, с. $34 ; 17$, c. 73]. В силу автономного характера такого обязательства, решить эту проблему в рамках основного договора, в который была включена арбитражная оговорка (или по поводу которого было составлено арбитражное соглашение), не всегда представляется возможным [1]. Однако ни в Нью-Йоркской конвенции 1958 г. и Европейской конвенции 1961 г., ни в ст. 1211 ГК РФ, в которой указаны правопорядки, подлежащие применению к договорным отношениям при отсутствии соглашения сторон о выборе права, не содержится общей нормы о праве, применимом к арбитражным соглашениям или оговоркам. В п. 2 ст. VI Европейской конвенции 1961 г. регламентированы лишь вопросы о наличии или действительности указанного арбитражного соглашения [5]. 
Для поиска применимого права в рассматриваемом случае возможно воспользоваться п. 1. ст. 1211 ГК РФ. Однако закрепленная там формула, что «при отсутствии соглашения сторон о подлежащем применению праве к договору применяется право страны, где на момент заключения договора находится место жительства или основное место деятельности стороны, которая осуществляет исполнение, имеющее решающее значение для содержания договора», вряд ли применима к арбитражному соглашению, так как определить, исполнение какой стороны имеет решающее значение в этом обязательстве, на наш взгляд, нереально. Поэтому должен использоваться критерий «тесной связи», установленный в п. 9 ст. 1211 ГК РФ, на основе которого, как пишет В.А. Канашевский, к арбитражной оговорке, очевидно, должно применяться право государства места проведения арбитража, поскольку именно с этим правом существует наиболее тесная связь [9, c. 658]. Однако в этом случае верно и другое его замечание, что вопрос о том, относится ли арбитражное соглашение к гражданско-правовым сделкам, является в отечественной правовой науке дискуссионным, и существуют противоположные суждения по этому поводу [16, с. 229, 232]. Поэтому определение применимого к арбитражному соглашению права на основе норм разд. VI ч. 3 ГК РФ представляется спорным. В связи с чем и чтобы снять возникшие трудности, мы предлагаем дополнить ст. 1211 ГК РФ пунктом 12 следующего содержания: «К арбитражным соглашениям (оговоркам) в случае отсутствия прямого указания в международном догово$\mathrm{pe}$, законе или соглашении сторон применяется право государства места проведения арбитражного разбирательства». Как нам представляется, такое законодательное решение будет совпадать и с мнением юридического сообщества $[10$, с. $81 ; 11$, с. 69], и со сложившейся судебной практикой [15].

Конфликтующие стороны самостоятельно определяют условия арбитражного соглашения, среди которых ключевыми являются условия о выборе вида, места, языке арбитража и порядке разбирательства и пр. Однако если ими это не сделано или выполнено лишь частично, то восполнить пробелы смо- гут уже арбитры на основе норм применимого права, а указанное выше предложение по дополнению отечественного законодательства подтвердит обоснованность и правомерность таких действий.

\section{Выводы}

Проведенное исследование позволяет прийти к следующим выводам.

Во-первых, соглашение о передаче спора в международный коммерческий арбитраж служит предпосылкой его разбирательства в подобном арбитраже, отражает принцип добровольности обращения к такому разбирательству и является правообразующим юридическим фактом, порождающим право суда на рассмотрение конкретных споров между сторонами. По своей юридической природе, содержанию, форме, способам реализации (видам), применимым принципам (добровольности и автономности) и т. п. арбитражное соглашение, заключенное для рассмотрения споров в международном коммерческом арбитраже и арбитраже внутренних споров, по сути, совпадает и имеет один и тот же юридический характер. Содержание арбитражного соглашения зависит от воли сторон, они сами определяют, из каких элементов оно будет состоять, и, как правило, в него включают выбор вида арбитража (институционный арбитраж или арбитраж ad hoc), места его проведения, языка (языков) и порядка арбитражного разбирательства, в том числе определение числа арбитров и т. п.

Во-вторых, наличие иностранного элемента несет в себе определенную специфику арбитражного соглашения в рамках международного коммерческого арбитража. В этом случае необходимо решить коллизионную проблему, то есть проблему выбора применимого права. Стороны могут самостоятельно, на основе принципа автономии воли решить этот вопрос в тексте арбитражного соглашения (оговорки), однако если ими этого не сделано, то ни действующее отечественное законодательство, ни нормы международных соглашений в этой области, участником которых является РФ, не содержат специального правила по выбору такого правопорядка. В связи с чем и чтобы снять возможность возникнове- 
ния проблем на практике, мы предлагаем дополнить ст. 1211 ГК РФ пунктом 12 следующего содержания: «К арбитражным соглашениям (оговоркам) в случае отсутствия прямого указания в международном договоре, законе или соглашении сторон применяется право государства места проведения арбитражного разбирательства».

Полагаем, такое законодательное решение будет совпадать и с мнением юридического сообщества, и со сложившейся судебной практикой. Более того, текст арбитражного соглашения (оговорки) сторон может быть неточным или иметь пробелы, восполнить эти недостатки смогут уже арбитры на основе норм применимого права, а указанное выше предложение по дополнению отечественного законодательства подтвердит обоснованность и правомерность таких действий.

\section{СПИСОК ЛИТЕРАТУРЫ}

1. Астахов, Д. О. Дискуссия о делокализации международного коммерческого арбитража в правовой доктрине / Д. О. Астахов // Ученые труды Российской академии адвокатуры и нотариата. 2018. - № 4 (51). - C. 143-146.

2. Бодрова, О. Реформа третейского законодательства / О. Бодрова // ЭЖ-Юрист. - 2016. № 11. - C. 8 .

3. Васин, В. Н. Латинизмы в гражданском праве : учеб.-метод. пособие / В. Н. Васин, В. И. Казанцев, Н. К. Нарозников. - М. : ВГНА МНС РФ : Кн. мир, 2004. -115 c.

4. Дмитриева, Г. К. Международный коммерческий арбитраж : учеб.-практ. пособие / Г. К. Дмитриева. - М. : Проспект, 1997. - 227 с.

5. Европейская конвенция о внешнеторговом арбитраже (Заключена в г. Женеве 21.04.1961) (вместе со «Статусом Европейской конвенции о внешнеторговом арбитраже») : (по состоянию на 20.10.2016) // Вестник Высшего арбитражного суда Российской Федерации. - 1993. - № 10.

6. Закон РФ от 07.07.1993 № 5338-1 «О международном коммерческом арбитраже» (вместе с «Положением о Международном коммерческом арбитражном суде при Торгово-промышленной палате Российской Федерации», «Положением о Морской арбитражной комиссии при Торгово-промышленной палате Российской Федерации») // Российская газета. - 1993. - 14 авг. (№ 156).

7. Иншакова, А. О. Предпосылки популяризации и реформы правовых основ деятельности МКА в РФ / А. О. Иншакова // Юрист. - 2016. - № 14. C. 24-27.

8. Иншакова, А. О. Трансформация регламентации деятельности и компетенции международного коммерческого арбитража (экономикоправовые потребности современного хозяйствования) / А. О. Иншакова, С. В. Николюкин, М. А. Алексеев; под ред. А. О. Иншаковой, С. В. Николюкина. - М. : Юрлитинформ, 2012. - 176 с.

9. Канашевский, В. А. Международные сделки: правовое регулирование / В. А. Канашевский. М. : Междунар. отношения, 2016. - 664 с.

10. Карабельников, Б. Р. Исполнение решений международных коммерческих арбитражей. Комментарий к Нью-Йоркской конвенции 1958 г. и главам 30 и 31 АПК РФ / Б. Р. Карабельников. - 3-е изд., перераб. и доп. - М. : Статут, 2008. - 606 с.

11. Комарова, Г. В. Признание и приведение в исполнение арбитражных решений в практике Арбитражного суда города Москвы / Г. В. Комарова // Вестник Арбитражного суда города Москвы. 2007. - № 5. - C. 59-69.

12. Латинские юридические изречения / сост. Е. И. Темнов. - М. : Юристь, 1966. -400 с.

13. Лунц, Л. А. Курс международного частного права / Л. А. Лунц. - М. : Спарк, 2002. - 1007 c.

14. Пискунов, Я. Третейское разбирательство - это не бизнес : [интервью с М.Л. Гальпериным] / Я. Пискунов // Закон. - 2015. - № 10. - С. 6-16.

15. Постановление Президиума ВАС РФ от 22.09.2009 № 5604/09 по делу № A57-8082/2008-116 // Вестник Высшего арбитражного суда Российской Федерации. - 2010. - № 1. - С. 68-72.

16. Рожкова, М. А. Договорное право: соглашение о подсудности, международной подсудности, примирительной процедуре, арбитражное (третейское) и мировое соглашения / М. А. Рожкова, Н. Г. Елисеев, О. Ю. Скворцов ; под общ. ред. М. А. Рожковой. - М. : Статут, 2008. - 283 с.

17. Современное международное частное право в России и Евросоюзе. Кн. 1 : монография / под ред. М. М. Богуславского, А. Г. Лисицина-Светланова, А. Тунка. - М. : Норма, 2013. - 656 с.

18. Федеральный закон от 29.11.2015 № 382-Ф3 «Об арбитраже (третейском разбирательстве) в Российской Федерации» // Собрание законодательства Российской Федерации. - 2016. - № 1 (ч. I). - Ст. 2.

19. Шмиттгофф, К. М. Экспорт: право и практика международной торговли : пер. с англ. / К. М. Шмиттгофф. - М. : Юрид. лит., 1993. -512 с.

\section{REFERENCES}

1. Astakhov D.O. Diskussiya o delokalizatsii mezhdunarodnogo kommercheskogo arbitrazha $\mathrm{v}$ 
pravovoy doktrine [Discussion on the International Commercial Arbitration Delocalization in the Legal Doctrine]. Uchenye trudy Rossiyskoy akademii advokatury $i$ notariata [Scientific Works of the Russian Academy of Advocacy and Notary], 2018, no. 4(51), pp. 143-146.

2. Bodrova O. Reforma treteyskogo zakonodatelstva [The Reform of the Arbitration Law]. EZh-Yurist, 2016, no. 11, p. 8.

3. Vasin V.N., Kazantsev V.I., Naroznikov N.K. Latinizmy v grazhdanskom prave: ucheb.-metod. posobie [Latinisms in Civil Law: Study Guide]. Moscow, Tax Academy of the Russian Federation, Knizhnyy mir Publ., 2004. 115 p.

4. Dmitrieva G.K. Mezhdunarodnyy kommercheskiy arbitrazh: ucheb.-prakt. posobie [International Commercial Arbitration: Study Guide]. Moscow, Prospekt Publ., 1997. 227 p.

5. Evropeyskaya konventsiya o vneshnetorgovom arbitrazhe (Zaklyuchena v g. Zheneve 21.04.1961) (vmeste so «Statusom Evropeyskoy konventsii o vneshnetorgovom arbitrazhe»): (po sostoyaniyu na 20.10.2016) [The European Convention on Foreign Trade Arbitration (Signed in Geneva on Apr. 21, 1961) (with "The Status of the European Convention on the Foreign Trade Arbitration": as of 20 Oct. 2016)]. Vestnik Vysshego arbitrazhnogo suda Rossiyskoy Federatsii [Supreme Court of Arbitration of the Russian Federation Bulletin], 1993, no. 10.

6. Zakon RF ot 07.07.1993 № 5338-1 «O mezhdunarodnom kommercheskom arbitrazhe» (vmeste s «Polozheniem o Mezhdunarodnom kommercheskom arbitrazhnom sude pri Torgovopromyshlennoy palate Rossiyskoy Federatsii», «Polozheniem o Morskoy arbitrazhnoy komissii pri Torgovo-promyshlennoy palate Rossiyskoy Federatsii») [Law of the Russian Federation, dated 07 July 1993, No. 5338-1 “On International Commercial Arbitration" (with "Regulations on the International Commercial Arbitration Court at the Chamber of Commerce and Industry of the Russian Federation", "Regulations on the Maritime Arbitration Commission at the Chamber of Commerce and Industry of the Russian Federation")]. Rossiyskaya gazeta, 1993, 14 Aug. (no.156).

7. Inshakova A.O. Predposylki populyarizatsii i reformy pravovykh osnov deyatelnosti MKA v RF [Preconditions for Promoting and Reforming Legal Basis of the Activities of the ICA in the Russian Federation]. Yurist, 2016, no. 14, pp. 24-27.

8. Inshakova A.O., Nikolyukin S.V., Alekseev M.A. Transformatsiya reglamentatsii deyatelnosti $i$ kompetentsii mezhdunarodnogo kommercheskogo arbitrazha (ekonomiko-pravovye potrebnosti sovremennogo khozyaystvovaniya) [Transformation of Regulating the Activities and Competence of the
International Commercial Arbitration (Economic and Legal Requirements of Modern Management)]. Moscow, Yurlitinform Publ., 2012. 176 p.

9. Kanashevskiy V.A. Mezhdunarodnye sdelki: pravovoe regulirovanie [International Transactions: Legal Regulation]. Moscow, Mezhdunarodnye otnosheniya Publ., 2016. 664 p.

10. Karabelnikov B.R. Ispolnenie resheniy mezhdunarodnykh kommercheskikh arbitrazhey. Kommentariy k Nyu-Yorkskoy konventsii 1958 g. $i$ glavam 30 i 31 APK RF [Execution of Decisions of the International Commercial Arbitrations. Comment on the New York Convention of 1958 and Chapters 30 and 31 of the Arbitration Procedural Code of the Russian Federation]. Moscow, Statut Publ., 2008. 606 p.

11. Komarova G.V. Priznanie i privedenie v ispolnenie arbitrazhnykh resheniy $\mathrm{v}$ praktike Arbitrazhnogo suda goroda Moskvy[Recognition and Enforcement of Arbitral Decisions in the practice of the Arbitration Court of Moscow]. Vestnik Arbitrazhnogo suda goroda Moskvy [Arbitration Court of Moscow Bulletin], 2007, no. 5, pp. 59-69.

12. Temnov E.I., ed. Latinskie yuridicheskie izrecheniya [Latin Legal Sayings]. Moscow, Yurist Publ., 1966. 400 p.

13. Lunts L.A. Kurs mezhdunarodnogo chastnogo prava [Course of International Private Law]. Moscow, Spark Publ., 2002. 1007 p.

14. Piskunov Ya. Treteyskoe razbiratelstvo - eto ne biznes: [intervyu s M.L. Galperinym] [Arbitration is not a business: [Interview with M.L. Galperin]]. Zakon, 2015. no. 10, pp. 6-16.

15. Postanovlenie Prezidiuma VAS RF ot 22.09.2009 № 5604/09 podelu № A57-8082/2008-11 [The Resolution of the Presidium of the SAC of the Russian Federation dated 22 Sep. 2009 No. 5604/09 on case A57-8082/2008116]. Vestnik Vysshego arbitrazhnogo suda Rossiyskoy Federatsii [Supreme Court of Arbitration of the Russian Federation Bulletin], 2010, no. 1, pp. 68-72.

16. Rozhkova M.A., Eliseev N.G., Skvortsov O.Yu. Dogovornoe pravo: soglashenie o podsudnosti, mezhdunarodnoy podsudnosti, primiritelnoy protsedure, arbitrazhnoe (treteyskoe) $i$ mirovoe soglasheniya [Contract Law: the Agreement on Jurisdiction, International Jurisdiction, Conciliation Procedure, Arbitration and Settlement Agreement]. Moscow, Statut Publ., 2008. 283 p.

17. Boguslavskiy M.M., Lisitsin-Svetlanov A.G., Tunk A., eds. Sovremennoe mezhdunarodnoe chastnoe pravo v Rossii $i$ Evrosoyuze. Kn. 1: monografiya [Modern International Private Law in Russia and the European Union. Book 1: Monograph]. Moscow, Norma Publ., 2013. 656 p.

18. Federalnyy zakon ot 29.11.2015 № 382-FZ «Ob arbitrazhe (treteyskom razbiratelstve) V Rossiyskoy Federatsii» [Federal Law of 29 Nov. 2015 
No. 382-FZ "On Arbitration in the Russian Federation”]. Sobranie zakonodatel'stva Rossiyskoy Federatsii [Collection of Legislative Acts of the Russian Federation], 2016, no.1 (Part 1), art. 2.
19. Shmittgoff K.M. Eksport: pravo i praktika mezhdunarodnoy torgovli [Exports: Law and Practice of International Trade]. Moscow, Yuridicheskaya literatura Publ., 1993. $512 \mathrm{p}$.

\section{Information about the Author}

Irina A. Stepanova, Notary of Volgograd, Marshala Eremenko St., 19, 400123 Volgograd, Russian Federation; Candidate for a Degree of the Department of Civil Law and Process and International Private Law, Peoples' Friendship University of Russia, Miklukho-Maklaya St., 6, 117198 Moscow, Russian Federation, sia-may@yandex.ru, https://orcid.org/0000-0003-2296-9368

\section{Информация об авторе}

Ирина Александровна Степанова, нотариус города Волгограда, ул. им. Маршала Еременко, 19, 400123 г. Волгоград, Российская Федерация; соискатель кафедры гражданского права и процесса и международного частного права, Российский университет дружбы народов, ул. Миклухо-Маклая, 6, 117198 г. Москва, Российская Федерация, sia-may@yandex.ru, https://orcid.org/0000-0003-2296-9368 